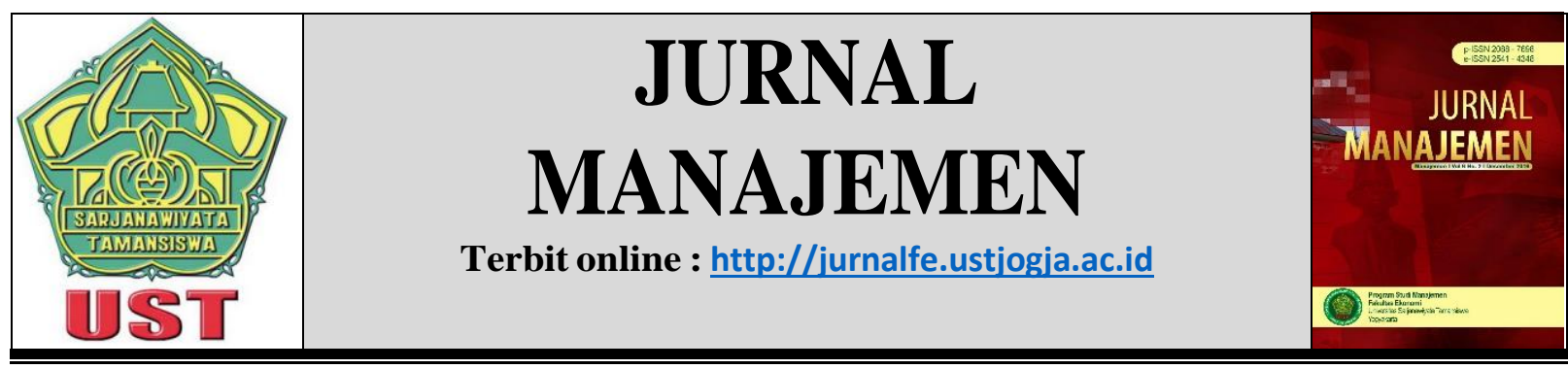

\title{
PENGARUH MOTIVASI DAN KEPUASAN KERJA TERHADAP KOMITMEN ORGANISASIONAL SERTA DAMPAKNYA PADA KINERJA KARYAWAN (Studi Kasus Pada Manajemen Pusat Waroeng Spesial Sambal Yogyakarta)
}

\author{
Tri Wahyuni ${ }^{1}$ \\ Soni Kurniawan ${ }^{2}$
}

Universitas Sarjanawiyata Tamansiswa Yogyakarta ${ }^{1,2}$

Korespondensi : wahyuni.tri1911@gmail.com

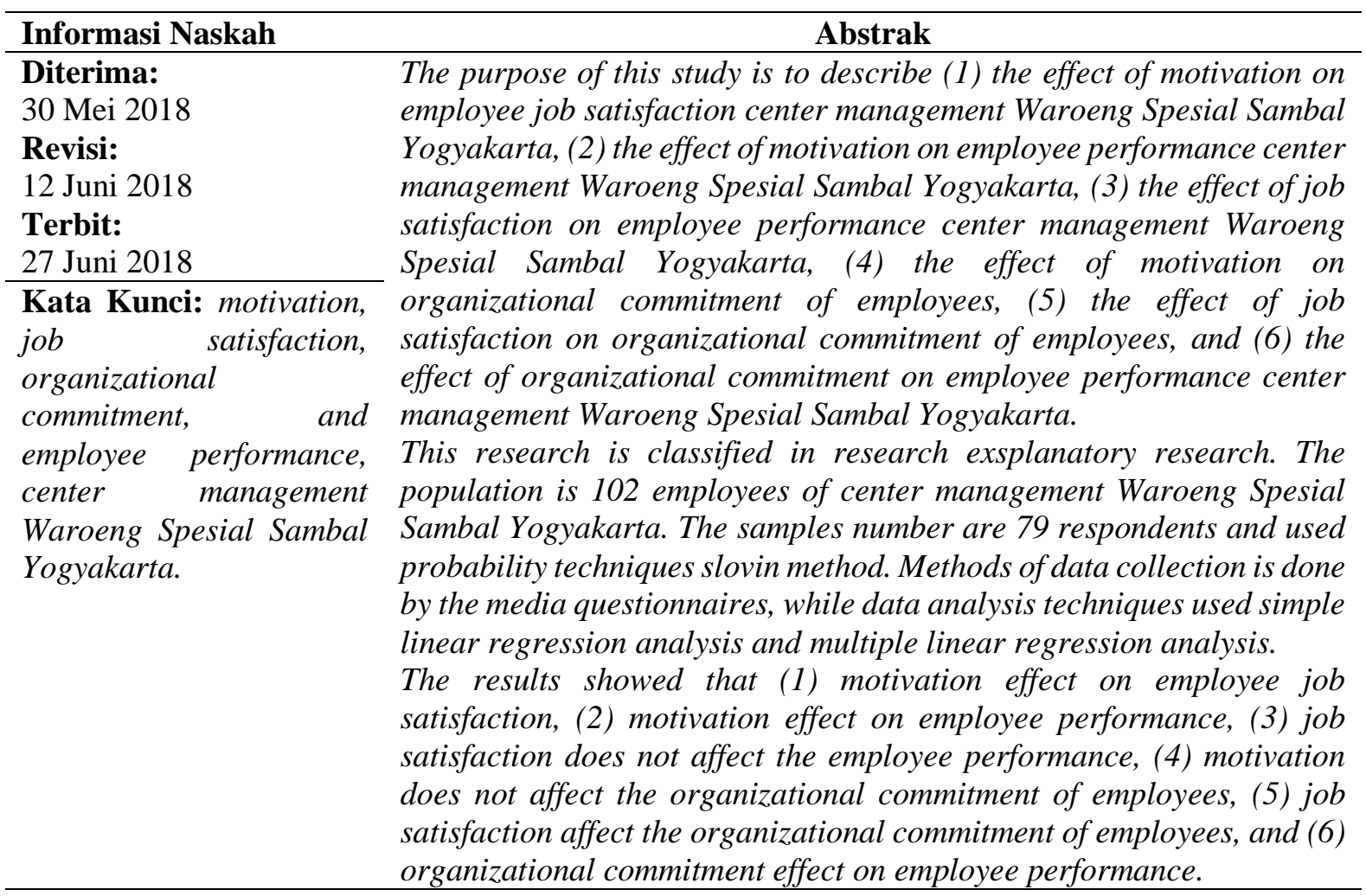

\section{PENDAHULUAN}

Peran fungsi karyawan atau tenaga kerja dalam organisasi atau perusahaan semakin mendapat perhatian dalam aktifitas tujuan organisasi atau perusahaan. Pada masa sekarang sumber daya manusia menjadi investasi terpenting yang mungkin dilakukan oleh suatu perusahaan. Sistem pengelolaan sumber daya manusia yang tepat merupakan kunci keberhasilan organisasi untuk mencapai tujuannya dan terus menjamin keberlangsungan organisasi atau perusahaan tersebut. Oleh karenanya untuk menentukan berhasil atau 
tidaknya pencapaian tujuan organisasi pelaksanaan kinerja karyawan yang optimal sangat diperlukan (Veithzal Rivai, 2004:309).

Waroeng Spesial Sambal sebagai salah satu perusahaan kuliner di Yogyakarta yang sudah memiliki eksistensi cukup lama dan mengembangkan cabangnya hingga ke berbagai daerah juga menyadari akan pentingnya suatu kinerja karyawan. Waroeng Spesial Sambal (Waroeng SS) merupakan hasil pemikiran dari seorang Bapak Yoyok Heri Wahyono bersama teman-temannya yang berdiri sejak tahun 2002 dan awalnya berupa waroeng tenda di Jalan Kaliurang sebelah barat Graha Sabha Pramana UGM namun tahun ini sudah terdiri dari 73 cabang dan 4 franchise yang tersebar di berbagai kota di Indonesia dengan area utama Yogyakarta, Purwokerto, Semarang, Solo, Jakarta, Bogor, Tangerang, dan Malang Raya.

Semakin berkembangnya usaha kuliner ini, mengharuskan Waroeng SS membentuk suatu sistem manajemen yang lebih terstuktur sehingga manajemen pusat pun dibentuk pada awal tahun 2011 dengan struktur pengelolaannya yang sudah terkoordinasi dengan baik di Jalan Kaliurang Km 4,5 Gang Kinanti No. 19 Mlati Sleman, Yogyakarta dengan karyawan yang berjumlah 102 orang. Area Waroeng SS yang cukup luas pun tentu menjadi suatu perhatian oleh manajemen pusat yang harus dapat mengsinkronisasikan keberhasilan antar area. Untuk terus bertahan dalam persaingan dan mencapai keberhasilan di setiap area Waroeng SS tentu bukanlah hal yang mudah bagi sistem manajemen pusat Waroeng SS karena ketika suatu perusahaan semakin besar masalah pasti akan tetap muncul.

Pada dasarnya dalam suatu sasaran organisasi berupa kinerja karyawan dapat tercapai salah satunya dengan memperhatikan sejumlah faktor. Faktor-faktor tersebut salah satunya adalah faktor internal karyawan yang diperoleh dalam diri karyawan dan diperoleh saat ia berkembang misalnya adalah motivasi dan kepuasan kerja (Wirawan, 2009:6). Motivasi kerja dapat diartikan sebagai proses yang menjelaskan intensitas, arah, dan ketekunan usaha untuk mencapai suatu tujuan (Robbins dan Timothy, 2008:222). Apa pun yang dilakukan karyawan bila termotivasi akan menghasilkan kepuasan kerja tersendiri. Karena menurut Siagian (1997) dalam Octaviana (2011) salah satu cara untuk menghasilkan kepuasan kerja karyawan adalah dengan memenuhi kebutuhan-kebutuhan karyawan agar motivasi kerja mereka menjadi tinggi. Penelitian oleh Brahmasari dan Agus (2008) menunjukkan motivasi kerja berpengaruh positif dan signifikan terhadap kepuasan kerja karyawan.

Dengan adanya motivasi yang tepat pula karyawan akan terdorong untuk berbuat semaksimal mungkin dalam melaksanakan tugasnya. Karyawan yang merasa puas terhadap pekerjaannya dan menganggap pekerjaannya sebagai sesuatu yang menyenangkan pun akan cenderung memiliki kinerja yang baik. Menurut penelitian (Wahab, 2012) bahwa motivasi dan kepuasan kerja secara bersama-sama berpengaruh signifikan terhadap kinerja karyawan. Motivasi dan kepuasan kerja juga berkaitan dengan komitmen organisasional karyawan (Mathiew dan Jones, 1991, dalam Tania, 2013). Komitmen dari seorang karyawan terhadap organisasinya dapat menjadi bagian instrumen penting untuk meningkatkan kinerja dari karyawan tersebut (Khan, Ziauddin, Farooq, dan Muhammad, 2010). Penelitian Khan et al. (2010) menunjukkan bahwa adanya hubungan positif antara komitmen organisasional terhadap kinerja karyawan.

Tujuan penelitian ini adalah 1) Untuk mengetahui signifikansi pengaruh positif motivasi terhadap kepuasan kerja karyawan pada manajemen pusat Waroeng SS Yogyakarta; 2) Untuk mengetahui signifikansi pengaruh positif motivasi terhadap kinerja karyawan pada manajemen pusat Waroeng SS Yogyakarta; 3) Untuk mengetahui signifikansi pengaruh positif kepuasan kerja terhadap kinerja karyawan pada manajemen pusat Waroeng SS Yogyakarta; 4) Untuk mengetahui signifikansi pengaruh positif motivasi terhadap komitmen organisasional karyawan pada manajemen pusat Waroeng SS 
Yogyakarta; 5) Untuk mengetahui signifikansi pengaruh positif kepuasan kerja terhadap komitmen organisasional karyawan pada manajemen pusat Waroeng SS Yogyakarta; 6) Untuk mengetahui signifikansi pengaruh positif komitmen organisasional terhadap kinerja karyawan pada manajemen pusat Waroeng SS Yogyakarta.

\section{LANDASAN TEORI DAN HIPOTESIS}

\subsection{Pengaruh Antar Variabel}

\subsubsection{Pengaruh Motivasi Terhadap Kepuasan Kerja}

Kepuasan kerja dapat diartikan sebagai sebuah efektivitas atau respon emosional terhadap berbagai aspek pekerjaan. Keadaan emosional yang menyenangkan atau tidak menyenangkan muncul disebabkan karena pada saat karyawan bekerja mereka membawa serta keinginan, kebutuhan, dan pengalaman masa lalu yang membentuk harapan kerja. Motivasi kerja karyawan mendorong munculnya tindakan dalam rangka memenuhi keinginan, kebutuhan, dan harapan kerja tersebut (Kreitner dan Angelo (2005:271).

Motivasi yang ada pada seseorang akan mewujudkan suatu perilaku yang diarahkan untuk mencapai kepuasan kerja. Menurut Brahmasari dan Agus (2008) dalam penelitiannya motivasi kerja berpengaruh positif dan signifikan terhadap kepuasan kerja karyawan. Berdasarkan uraian tersebut, maka hipotesis yang diajukan dalam penelitian ini:

\section{Kerja.}

H1 : Motivasi Berpengaruh Positif Signifikan Terhadap Kepuasan

\subsubsection{Pengaruh Motivasi Terhadap Kinerja Karyawan}

Kinerja karyawan menjadi sangat penting karena penurunan kinerja baik individu maupun kelompok dalam suatu perusahaan dapat memberi dampak yang berarti dalam suatu perusahaan. Memberi motivasi bagi bawahannya adalah salah satu hal yang bisa dilakukan seorang manajer atau pimpinan. Munandar (2001) dalam Devi (2009) mengungkapkan bahwa kinerja adalah hasil interaksi antara motivasi kerja, kemampuan (abilities), dan peluang (opportunities). Dalam penelitian Koesmono (2005) bahwa motivasi berpengaruh positif terhadap kinerja karyawan. karena karyawan yang memiliki motivasi yang tinggi akan menghasilkan kinerja yang tinggi pula. Berdasarkan uraian tersebut, maka hipotesis yang diajukan dalam penelitian ini :

\section{Karyawan.}

H2 : Motivasi Berpengaruh Positif Signifikan Terhadap Kinerja

\section{Pengaruh Kepuasan Kerja Terhadap Kinerja Karyawan}

Menurut Al Ahmadi (2009) dalam Pangestu (2014) kepuasan kerja memengaruhi kinerja seseorang. Perusahaan hendaknya memberikan perhatian terhadap kepuasan kerja karyawannya. Karena apabila karyawan puas terhadap pekerjaannya karyawan akan lebih giat dalam melaksanakan pekerjaannya. Kepuasan kerja yang tinggi sangat mempengaruhi kondisi kerja yang positif dan dinamis sehingga mampu memberikan keuntungan yang nyata, tidak hanya bagi perusahaan tetapi bagi karyawan itu sendiri.

Pada penelitian terdahulu juga dikemukakan bahwa kepuasan kerja memiliki pengaruh yang signifikan terhadap kinerja karyawan, seperti yang dikemukakan oleh Mahesa (2010) dan Octaviana (2011), serta Burhanudin Wahab (2012) menyatakan kepuasan kerja berpengaruh terhadap kinerja Karyawan pada PT. Bank Mandiri (Persero) Tbk Makassar. Berdasarkan uraian tersebut, maka hipotesis yang diajukan dalam penelitian ini :

H3 : Kepuasan Kerja Berpengaruh Positif Signifikan Terhadap Kinerja Karyawan. 


\subsubsection{Pengaruh Motivasi Terhadap Komitmen Organisasional}

Upaya pemberian motivasi merupakan salah satu cara untuk mewujudkan komitmen kerja karyawan pada perusahaan. Hal tersebut didukung oleh pernyataan Nickels (2009:336) dalam Wardhani (2015) yang menjelaskan hubungan antara motivasi dan komitmen organisasional, bahwa "pekerja (karyawan) yang tidak senang kemungkinan besar akan meninggalkan perusahaan dan perusahaan biasanya mengalami kerugian". Pernyataan tersebut beranggapan apabila karyawan memiliki motivasi yang tinggi maka mereka akan senang dan menikmati pekerjaan yang diberikan oleh perusahaan, sehingga karyawan mempunyai loyalitas dan komitmen terhadap perusahaan dimana karyawan tersebut bekerja.

Dalam suatu penelitian oleh Burton, Lee, dan Holtom (2002) menyatakan bahwa motivasi karyawan berpengaruh signifikan positif terhadap komitmen yang diukur melalui tiga dimensi dari komitmen, yaitu affective commitment, normative commitment, dan continuance commitment. Alimohammadi dan Ali (2013) juga mendukung bahwa motivasi kerja memiliki dampak positif signifikan terhadap komitmen organisasional. Berdasarkan uraian, berikut hipotesis yang diajukan dalam penelitian ini :

H4 : Motivasi Berpengaruh Positif Signifikan Terhadap Komitmen Organisasional.

\subsubsection{Pengaruh Kepuasan Kerja Terhadap Komitmen Organisasional}

Kepuasan kerja merupakan aspek pertama yang dicapai sebelum seorang karyawan memiliki komitmen organisasional, dimana menurut Gunlu, Mehmet, dan Nil (2010), kepuasan kerja memiliki pengaruh yang signifikan terhadap komitmen organisasional. Namun penelitian lain menyatakan bahwa variabel komitmen organisasional telah mendahului kepuasan kerja sesuai dengan pendapat Bateman dan Strasser (1984) dalam Devi (2009). Untuk merekonsiliasi temuan yang saling bertentangan maka Ferris (1981) dalam Devi (2009) menyatakan bahwa sifat dari komitmen organisasional dapat berubah sepanjang waktu.

Kepuasaan kerja dan komitmen organisasional cenderung memengaruhi satu sama lain (Pangestu, 2014). Seseorang yang puas dengan pekerjaannya akan lebih berkomitmen pada organisasi. Hasil penelitian McNeese-Smith (1996) juga menunjukkan adanya hubungan pengaruh antara kepuasan kerja dan komitmen organisasional, demikian pula dengan penelitian Yousef (2002). Berdasarkan uraian tersebut, maka hipotesis yang diajukan dalam penelitian ini :

H5 : Kepuasan Kerja Berpengaruh Positif Signifikan Terhadap Komitmen Organisasional.

\subsubsection{Pengaruh Komitmen Organisasional Terhadap Kinerja Karyawan}

Menurut Al Ahmadi (2009) dalam Pangestu (2014) komitmen organisasional dapat meningkatkan kinerja pegawai. Karena, dengan terciptanya komitmen organisasional yang tinggi, akan membuat pegawai mencintai dan turut merasa memiliki perusahaaan. Karyawan yang mencintai dan mengabdikan diri sepenuhnya kepada organisasi akan meningkatkan hasil kerja bagi organisasi.

Khairun Rozikin, (2012) menjelaskan bahwa terdapat pengaruh yang positif dan signifikan antara komitmen organisasi terhadap kinerja karyawan. Hasil penelitian dari McNeese-Smith (1996) menunjukkan pula hubungan antara kepuasan kerja dan komitmen organisasional. Berdasarkan uraian tersebut, maka hipotesis yang diajukan dalam penelitian ini adalah H6 : komitmen organisasional berpengaruh positif signifikan terhadap kinerja karyawan. 


\section{METODE PENELITIAN}

\subsection{Sifat Penelitian}

Berdasarkan pada hubungan antar variabel pada obyek yang diteliti maka penelitian ini bersifat sebab akibat atau disebut hubungan kausal. peneliti menggunakan pendekatan kuantitatif karena analisis penelitian berdasarkan pada teori-teori yang sudah ada dan berhubungan dengan topik penelitian.

\subsection{Variabel Penelitian dan Definisi Operasional} berikut.

Penelitian ini menggunakan tiga variabel dan definisi operasional sebagai

a. Variabel bebas/independen adalah motivasi yang menggunakan indikator berdasarkan teori kebutuhan McClelland (kebutuhan akan prestasi, kekuasaan, dan afiliasi). Variabel motivasi kerja diukur dengan instrumen yang dikembangkan oleh teori kebutuhan McClelland dengan instrumen baku dari Parrek, Udai (1985, dalam Mas'ud, 2004).

b. Variabel terikat/dependen adalah kinerja karyawan dan kepuasan kerja. Kinerja karyawan menggunakan item indikator dan pengembangan kuesioner menurut Tsui, Anne S., Jone L. Pearce, dan Lyman (1997, dalam Mas'ud 2004) yaitu kuantitas kerja karyawan, kualitas kerja karyawan, efisiensi karyawan, usaha karyawan, standar profesional karyawan, kemampuan karyawan terhadap pekerjaan inti, ketepatan karyawan, dan pengetahuan serta kreativitas karyawan. Sedangkan kepuasan kerja menggunakan item indikator menurut Celluci dan De Vries (1978) dalam Kiasatina (2015) dan diukur dengan instrumen baku dari Celluci, Anthony J., dan David L. (1985, dalam Mas'ud, 2004).

c. Variabel perantara/intervening adalah komitmen organisasional menggunakan dimensi komitmen organisasional yang diungkapkan Allen dan Meyer (1991, dalam Nurhayati 2013) dan pengembangan kuesioner diukur sesuai yang dikemukakan oleh Meyer, J. P., Natalie J. Allen, dan Cathrine A. Smith (1993, dalam Mas'ud, 2004).

\subsection{Populasi, Sampel, dan Teknik Pengambilan Sampel}

Populasi penelitian ini adalah karyawan manajemen pusat Waroeng Spesial Sambal Yogyakarta yang terletak di Jalan Kaliurang Km 4,5 Gang Kinanti No. 19 Mlati Sleman, Yogyakarta dengan berjumlah 102 karyawan. Sampelnya adalah sebagian dari jumlah karyawan manajemen pusat Waroeng Spesial Sambal Yogyakarta yang terdiri dari divisi operasi, divisi support, dan non struktural. Teknik pengambilan sampel yang digunakan adalah dengan probability sampling. Selanjutnya teknik sampelnya adalah dengan metode slovin, yaitu teknik menentukan seberapa besar minimal sampel yang dibutuhkan jika ukuran populasi sudah diketahui. Menurut rumus metode slovin adalah sebagai berikut (Wiyono, 2011:78).

$$
\mathrm{n}=\frac{\mathrm{N}}{1+\mathrm{Ne}^{2}}
$$

Keterangan $: \mathrm{n}=$ Ukuran sampel

$\mathrm{N}=$ Populasi

$\mathrm{e}=$ Margin of Error Maximum, yaitu tingkat kesalahan maksimum yang masih bisa ditolerir (ditentukan 5\%)

Berdasarkan data yang diperoleh dengan jumlah populasi karyawan yang sudah diketahui dapat ditentukan jumlah sampel dalam penelitian ini, sebagai berikut. 


$$
\begin{aligned}
\mathrm{n}= & \frac{102}{1+102(0,05)^{2}} \\
\mathrm{n} & =79
\end{aligned}
$$

Jumlah sampel yang diambil (dibulatkan) adalah sebanyak 79 responden.

\subsection{Teknik Analisis Data}

Data hasil penelitian dianalisis dengan alat statistik yang terdiri dari uji kualitas data (uji validitas dan reliabilitas), analisis deskriptif, uji asumsi klasik (uji normalitas, uji heterokedastisitas dan uji multikolonieritas), analisis regresi sederhana dan berganda, serta analisis jalur, yang diolah dengan menggunakan SPSS 17.00 for Windows.

\section{HASIL PENELITIAN DAN PEMBAHASAN}

\subsection{Hasil Uji Kualitas Data (Uji Validitas dan Reliabilitas)}

Uji validitas dilakukan dengan membandingkan $r$ hitung dengan $r$ tabel (0.1864), apabila $\mathrm{r}$ hitung > $\mathrm{r}$ tabel maka dapat dinyatakan valid. Hasil uji validitas menunjukkan bahwa dari 6 item pernyataan motivasi terdapat 1 item yang tidak valid sehingga 5 item pernyataan dinyatakan valid; dari 10 item pernyataan kepuasan kerja terdapat 1 item pernyataan yang tidak valid sehingga 9 item pernyataan dinyatakan valid; sedangkan seluruh item pernyataan komitmen organisasional (6 item) dinyatakan valid; begitu pula dengan kinerja karyawan seluruh item pernyataan ( 8 item) dinyatakan valid.

Uji realibilitas terhadap seluruh item/pernyataan dalam penelitian ini menggunakan formula Cronbach Alpha (koefisien Alpha Cronbach), dimana secara umum dianggap reliabel apabila nilai Cronbach Alphanya > 0,70 dengan 0,900 (Nunnally, 1994 dalam Gozali, 2011).

Tabel 1. Uji Reliabilitas

\begin{tabular}{lccc}
\hline \multicolumn{1}{c}{ Variabel } & $\begin{array}{c}\text { Cronbach } \\
\text { Alpha }\end{array}$ & $\begin{array}{c}\text { Minimal Cronbach Alpha } \\
\text { yang disyaratkan }\end{array}$ & Keterangan \\
\hline Motivasi & 0,717 & 0,70 & Reliabel \\
Kepuasan Kerja & 0,797 & 0,70 & Reliabel \\
Komitmen & 0,747 & 0,70 & Reliabel \\
Organisasional & 0,751 & 0,70 & Reliabel \\
Kinerja Karyawan & 0, & & \\
\hline
\end{tabular}

Sumber: Data primer diolah, 2016.

\subsection{Hasil Analisis Deskriptif}

\subsubsection{Analisis Karakteristik Responden}

Karakteristik responden yang dianalisis dalam penelitian ini meliputi jenis kelamin, pendidikan terakhir, bagian/departemen, lama kerja, usia, dan status yang disajikan pda tabel 2 berikut. 
Tabel 2. Karakteristik Responden

\begin{tabular}{|c|c|c|}
\hline Keterangan & Frekuensi & Persentase \\
\hline \multicolumn{3}{|l|}{ Jenis Kelamin } \\
\hline Laki-Laki & 38 & $48,1 \%$ \\
\hline Perempuan & 41 & $51,9 \%$ \\
\hline \multicolumn{3}{|l|}{ Pendidikan Terakhir } \\
\hline SMA & 16 & $20,3 \%$ \\
\hline Diploma & 18 & $22,8 \%$ \\
\hline Strata 1 (S1) & 44 & $55,7 \%$ \\
\hline Strata $2(\mathrm{~S} 2)$ & 1 & $1,2 \%$ \\
\hline \multicolumn{3}{|l|}{ Bagian/Departemen } \\
\hline Keuangan & 34 & $43,0 \%$ \\
\hline Non Struktural & 10 & $12,7 \%$ \\
\hline Operasi & 6 & $7,6 \%$ \\
\hline P3O & 2 & $2,5 \%$ \\
\hline PAPG & 4 & $5,1 \%$ \\
\hline Produksi & 2 & $2,5 \%$ \\
\hline $\mathrm{SDM}$ & 21 & $26,6 \%$ \\
\hline \multicolumn{3}{|l|}{ Lama Kerja } \\
\hline$<1$ tahun & 10 & $12,7 \%$ \\
\hline $1-3$ tahun & 42 & $53,1 \%$ \\
\hline 4-6 tahun & 23 & $29,1 \%$ \\
\hline$>6$ tahun & 4 & $5,1 \%$ \\
\hline \multicolumn{3}{|l|}{ Usia } \\
\hline 20-25 tahun & 42 & $53,2 \%$ \\
\hline 26-30 tahun & 24 & $30,3 \%$ \\
\hline 31-35 tahun & 10 & $12,7 \%$ \\
\hline$>35$ tahun & 3 & $3,8 \%$ \\
\hline \multicolumn{3}{|l|}{ Status } \\
\hline Lajang & 46 & $58,2 \%$ \\
\hline Menikah & 33 & $41,8 \%$ \\
\hline
\end{tabular}

Sumber: Data primer diolah, 2016.

\subsubsection{Analisis Deskripsi Kategorisasi Variabel}

Untuk menafsirkan tinggi rendahnya rata-rata jawaban responden, dibuat rentang skala dimana dari skala 5 point diperoleh rentan skala sebesar 0,8 $(5-1=4 / 5=0,8)$.

Tabel 3. Kategorisasi Variabel Penelitian

\begin{tabular}{lcc}
\hline \multicolumn{1}{c}{ Variabel } & Rata-rata & Keterangan \\
\hline Motivasi & 4,03 & Tinggi \\
Kepuasan Kerja & 3,79 & Tinggi \\
Kinerja Karyawan & 3,60 & Tinggi \\
Komitmen Organisasional & 3,50 & Tinggi \\
\hline
\end{tabular}

Sumber: Data primer diolah, 2016.

Berdasarkan di kategori tinggi dengan rata-rata sebesar 3,03 yang selanjutnya tabel 3 diketahui rata-rata penilaian responden terhadap variabel motivasi berada diikuti oleh variabel kepuasan kerja dengan rata-rata sebesar 3,79, kemudian diikuti variabel kinerja karyawan dengan nilai rata-rata sebesar 3,60, dan pada peringkat terakhir diperoleh variabel komitmen organisasional. 


\subsection{Uji Asumsi Klasik}

Uji asumsi klasik meliputi uji normalitas, heterokedastisitas, dan multikolonieritas. Uji normalitas menggunakan uji kolmogrov-Smirnov, dimana suatu data dikatakan normal apabila nilai asymp.sig (2-tailed) > 0,05 (Ghozali, 2011). Tabel 4 menunjukan model regresi berdisitribusi normal.

Tabel 4. Hasil Uji Normalitas

\begin{tabular}{lcccc}
\hline $\begin{array}{c}\text { Variabel } \\
\text { Independen }\end{array}$ & $\begin{array}{c}\text { Variabel } \\
\text { Dependen }\end{array}$ & $\begin{array}{c}\text { kolmogrov- } \\
\text { Smirnov }\end{array}$ & $\begin{array}{c}\text { asymp.sig } \\
\text { (2-tailed) }\end{array}$ & Keterangan \\
\hline M & KJ & 0,947 & 0,332 & Normal \\
M & KO & 0,722 & 0,675 & Normal \\
KJ & & & & \\
M & KK & 0,778 & 0,581 & Normal \\
KJ & & & & \\
KO & & &
\end{tabular}

Sumber: Data primer diolah, 2016.

\section{Uji Heteroskedastisitas}

Uji heterokedastisitas menggunakan uji park dimana suatu data dikatakan tidak terjadi heterokedastisitas apabila nilai sig > 0,05 (Ghozali, 2011). Tabel 5 menunjukan model menunjukan model regresi tidak terjadi gejala heterokedastisitas.

Tabel 5. Hasil Uji Heterokedastisitas

\begin{tabular}{lccc}
\hline $\begin{array}{c}\text { Variabel } \\
\text { Independen }\end{array}$ & $\begin{array}{c}\text { Variabel } \\
\text { Dependen }\end{array}$ & Sig & Keterangan \\
\hline M & KJ & 0,122 & $\begin{array}{c}\text { Tidak Terjadi } \\
\text { Heterokedastisitas }\end{array}$ \\
M & KO & 0,872 & Tidak Terjadi \\
KJ & & 0,167 & Heterokedastisitas \\
M & KK & 0,800 & Tidak Terjadi \\
KJ & & 0,651 & Heterokedastisitas \\
KO & & 0,380 & \\
\hline
\end{tabular}

Sumber: Data primer diolah, 2016

Uji multikolonieritas dilakukan dengan melihat nilai Variance Inflation Factor (VIF), apabila nilai VIF < 10 dan nilai tolerance $>0,1$ maka tidak terjadi gejala multikolonieritas (Ghozali, 2011). Tabel 6 menunjukan hasil uji multikolonieritas.

Tabel 6. Hasil Uji Multikolonieritas

\begin{tabular}{lcccc}
\hline $\begin{array}{c}\text { Variabel } \\
\text { Independen }\end{array}$ & $\begin{array}{c}\text { Variabel } \\
\text { Dependen }\end{array}$ & VIF & Tolerance & Keterangan \\
\hline M & KO & 1,834 & 0,732 & Tidak Terjadi \\
KJ & & 1,384 & 0,732 & Multikolonieritas \\
M & KK & 1,390 & 0,720 & Tidak Terjadi \\
KJ & & 1,626 & 0,615 & Multikolonieritas \\
KO & 1,208 & 0,827 & \\
\hline
\end{tabular}

Sumber: Data primer diolah, 2016 


\subsection{Pengujian Hipotesis dan Pembahasan}

\subsubsection{Uji Hipotesis}

Hasil analisis uji t menyatakan $\mathrm{H} 3$ dan $\mathrm{H} 4$ ditolak karena niai sig > 0,005, sedangkan $\mathrm{H} 1, \mathrm{H} 2, \mathrm{H} 5$, dan $\mathrm{H} 6$ diterima karena pada tabel diatas nilai sig sebesar $0,000<0,05$. Hasil uji ini dapat dilihat pada tabel 7 analisis regresi liner.

Tabel 7. Analisis Regresi Linier

\begin{tabular}{|c|c|c|c|c|}
\hline Model & Std Beta & T hitung & Sig & Adj $R^{2}$ \\
\hline \multicolumn{5}{|c|}{$\mathrm{KJ}=12,253+0,527 \mathrm{M}$} \\
\hline M & 0,527 & 5,435 & 0,000 & 0,268 \\
\hline \multicolumn{5}{|c|}{$\mathrm{KO}=10,504-0,070 M+0,448 K J$} \\
\hline M & $-0,070$ & $-0,571$ & 0,570 & \multirow{2}{*}{0,151} \\
\hline $\mathrm{KJ}$ & 0,448 & 3,650 & 0,000 & \\
\hline \multicolumn{5}{|c|}{$\mathrm{KK}=13,143+0,243 \mathrm{M}+0,105 \mathrm{KJ}+0,248 \mathrm{KO}$} \\
\hline M & 0,243 & 1,998 & 0,049 & \multirow{3}{*}{0,167} \\
\hline KJ & 0,105 & 0,794 & 0,430 & \\
\hline $\mathrm{KO}$ & 0,248 & 2,180 & 0,032 & \\
\hline
\end{tabular}

Sumber : Data primer diolah, 2016.

Berdasarkan analisis jalur diperoleh bahwa pengaruh tidak langsung pengaruh motivasi terhadap kinerja karyawan melalui komitmen organisasional $(-0,070 \times 0,248)$ menunjukkan bahwa hasil nilai koefisien pengaruh tidak langsung lebih kecil dibandingkan nilai koefisien pengaruh langsung motivasi terhadap kinerja karyawan $(-0,017<0,243)$. Hal ini menunjukkan bahwa tidak ada pengaruh tidak langsung sehingga variabel motivasi tidak dapat melalui variabel intervening yaitu komitmen organisasional dalam memengaruhi kinerja karyawan.

Sedangkan besarnya nilai pengaruh tidak langsung pengaruh kepuasan kerja terhadap kinerja karyawan melalui komitmen organisasional $(0,448$ x 0,248 )menunjukkan bahwa nilai koefisien pengaruh tidak langsung lebih besar dibandingkan nilai koefisien pengaruh langsung kepuasan kerja terhadap kinerja karyawan $(0,111>0,105)$. Hal ini menunjukkan bahwa ada pengaruh tidak langsung sehingga variabel kepuasan kerja dapat melalui variabel intervening yaitu komitmen organisasional dalam memengaruhi kinerja karyawan.

\subsubsection{Pembahasan}

\section{a. Pengaruh Motivasi Terhadap Kepuasan Kerja}

Berdasarkan hasil analisis regresi linier sederhana dan pengujian hipotesis menunjukkan bahwa nilai signifikansi motivasi terhadap kepuasan kerja adalah $0,000<0,05$ sedangkan koefisien regresi $\beta$ sebesar 0,527 . Artinya motivasi berpengaruh positif signifikan terhadap kepuasan kerja. Sehingga berdasarkan hasil penelitian, motivasi mampu meningkatkan kepuasan kerja karyawan manajemen pusat Waroeng Spesial Sambal Yogyakarta.

Hal ini sesuai dengan penelitian Brahmasari dan Agus (2008) yang menyatakan hal yang sama bahwa motivasi berpengaruh positif signifikan terhadap kepuasan kerja. 


\section{b. Pengaruh Motivasi Terhadap Kinerja Karyawan}

Berdasarkan hasil analisis data menunjukkan bahwa nilai signifikansi motivasi terhadap kinerja karyawan adalah 0,049 < 0,05 sedangkan koefisien regresi $\beta$ sebesar 0,243. Artinya motivasi berpengaruh positif signifikan terhadap kinerja karyawan.

Hal ini sesuai pula dalam penelitian Koesmono (2005) bahwa motivasi berpengaruh positif terhadap kinerja karyawan. karena karyawan yang memiliki motivasi yang tinggi akan menghasilkan kinerja yang tinggi pula. Maka semakin tinggi motivasi maka semakin tinggi pula kinerja karyawan manajemen pusat Waroeng Spesial Sambal Yogyakarta.

\section{c. Pengaruh Kepuasan Kerja Terhadap Kinerja Karyawan}

Dari hasil analisis regresi linier berganda dan pengujian hipotesis menunjukkan bahwa nilai signifikansi kepuasan kerja terhadap kinerja karyawan adalah 0,430 $>0,05$ sedangkan koefisien regresi $\beta$ sebesar 0,105. Artinya kepuasan kerja tidak berpengaruh terhadap kinerja karyawan. Secara keseluruhan faktor kepuasan kerja karyawan tidak mampu untuk meningkatkan kinerja karyawan manajemen pusat Waroeng Spesial Sambal Yogyakarta.

Hal ini berbanding terbalik dengan penelitian Mahesa (2010) dan Octaviana (2011) bahwa kepuasan kerja memiliki pengaruh yang signifikan terhadap kinerja karyawan.

\section{d. Pengaruh Motivasi Terhadap Komitmen Organisasional}

Berdasarkan hasil analisis data menunjukkan bahwa nilai signifikansi motivasi terhadap komitmen organisasional adalah 0,570 > 0,05 sedangkan koefisien regresi $\beta$ sebesar -0,070. Artinya motivasi tidak berpengaruh terhadap komitmen organisasional.Secara keseluruhan indikator motivasi karyawan tidak mampu untuk meningkatkan kinerja karyawan manajemen pusat Waroeng Spesial Sambal Yogyakarta

Sedangkan ini hal tersebut berbanding terbalik dengan penelitian Alimohammadi dan Ali (2013) bahwa motivasi kerja memiliki dampak positif signifikan terhadap komitmen organisasional.

\section{e. Pengaruh Kepuasan Kerja Terhadap Komitmen Organisasional}

Berdasarkan hasil analisis regresi linier sederhana dan pengujian hipotesis menunjukkan bahwa nilai signifikansi kepuasan kerja adalah 0,000 $<0,05$ sedangkan koefisien regresi $\beta$ sebesar 0,448 . Artinya kepuasan kerja berpengaruh positif signifikan terhadap komitmen organisasional. Dengan demikian karyawan manajemen pusat Waroeng Spesial Sambal Yogyakarta yang puas akan pekerjaannya akan terlihat mendekatkan diri pada organisasi sehingga komitmen organisasional pun makin meningkat.

Hal ini sesuai dengan penelitian McNeese-Smith (1996) yang juga menunjukkan adanya hubungan pengaruh antara kepuasan kerja dan komitmen organisasional. Penelitian Pangestu (2014) juga mengungkapkan bahwa kepuasaan kerja dan komitmen organisasional cenderung memengaruhi satu sama lain.

\section{f. Pengaruh Komitmen Organisasional Terhadap Kinerja Karyawan}

Berdasarkan hasil analisis data menunjukkan bahwa nilai signifikansi komitmen organisasional terhadap kinerja karyawan adalah 0,032 $<0,05$ sedangkan koefisien regresi $\beta$ sebesar 0,248 . Artinya komitmen organisasional berpengaruh positif signifikan terhadap kinerja karyawan. Maka komitmen 
organisasional adalah menunjuang untuk meningkatnya kinerja karyawan manajemen pusat Waroeng Spesial Sambal Yogyakarta.

Hal ini sesuai dengan penelitian Khairun Rozikin, (2012) yang menjelaskan bahwa terdapat pengaruh yang positif dan signifikan antara komitmen organisasi terhadap kinerja karyawan. Karyawan yang mencintai dan mengabdikan diri sepenuhnya kepada organisasi akan meningkatkan hasil kerja bagi organisasi.

\section{KESIMPULAN DAN SARAN}

Berdasarkan hasil penelitian yang sudah dilakukan dapat disimpulkan : 1) Motivasi berpengaruh positif signifikan terhadap kepuasan kerja karyawan pada manajemen pusat Waroeng Spesial Sambal Yogyakarta; 2) Motivasi berpengaruh positif signifikan terhadap kinerja karyawan pada manajemen pusat Waroeng Spesial Sambal Yogyakarta; 3) Kepuasan kerja tidak berpengaruh terhadap kinerja karyawan pada manajemen pusat Waroeng Spesial Sambal Yogyakarta; 4) Motivasi tidak berpengaruh terhadap komitmen organisasional karyawan pada manajemen pusat Waroeng Spesial Sambal Yogyakarta; 5) Kepuasan kerja berpengaruh positif signifikan terhadap komitmen organisasional karyawan pada manajemen pusat Waroeng Spesial Sambal Yogyakarta; 6) Komitmen organisasional berpengaruh positif signifikan terhadap kinerja karyawan pada manajemen pusat Waroeng Spesial Sambal Yogyakarta; 7) Motivasi tidak dapat melalui variabel intervening komitmen organisasional dalam memengaruhi kinerja karyawan manajemen pusat Waroeng Spesial Sambal Yogyakarta; 8) Kepuasan kerja dapat melalui variabel intervening komitmen organisasional dalam memengaruhi kinerja karyawan manajemen pusat Waroeng Spesial Sambal Yogyakarta.

Saran yang diberikan bagi manajemen pusat Waroeng Spesial Sambal Yogyakarta adalah manajemen pusat dapat meningkatkan kinerja karyawan dengan memperhatikan motivasi karyawan seperti mempertahankan dan meningkatkan kebutuhan prestasi, kebutuhan akan kekuasaan, dan kebutuhan afiliasi/bersahabat, sehingga dengan dimensidimensi motivasi tersebut dapat menciptakan kinerja karyawan yang lebih baik. Selain motivasi, manajemen pusat juga perlu memperhatikan kepuasan kerja karyawan seperti mempertahankan dan meningkatkan kepuasan kerja melalui indikator gaji, promosi, rekan kerja, hubungan dengan atasan, dan pekerjaan itu sendiri, maka diharapkan dapat menunjukkan tingkat komitmen organisasional yang baik pada setiap diri karyawan sehingga akan meningkatkan kinerja karyawan. Bagi peneliti selanjutnya dapat mengembangkan dengan meneliti faktor lain yang dapat memengaruhi kinerja karyawan karena faktor motivasi, kepuasan kerja, dan komitmen organisasional berpengaruh sebesar $16,7 \%$.

\section{DAFTAR PUSTAKA}

Alimohammadi, Meysam dan Ali J. (2013). Work Motivation And Organizational Commitment Among Iranian Employees. International Journal Of Research In Organizational Behaviour And Human ResourceManagement, Vol. 1(03), pp. 1-12.

Burton, James P., Lee Thomas W., dan Holtom Brooks C. (2002). The Influence of Motivation to Attend, Ability to Attend, and OrganizationalCommitment on Different Types of Absence Behaviors. Journal of Managerial Issues, Summer, pp. 181-197.

Devi, Eva Kris D. (2009). Analisis Pengaruh Kepuasan Kerja Dan Motivasi Terhadap Kinerja Karyawan Dengan Komitmen Organisasional Sebagai Variabel Intervening 
(Studi Pada Karyawan Outsourcing PT. Semeru Karya Buana Semarang). Published Tesis S2, Universiatas Diponegoro, Semarang.

Ghozali, Imam. (2011). Aplikasi Analisis Multivariate dengan Program SPSS. Semarang : BP Diponegoro.

Gunlu, Ebru, Mehmet Aksarayli, and Nil Ufer Sahin Percin. (2010). Job Satisfaction and Organizational Commitment of Hotel Managers in Turkey. International Journal of Contemporary Hospitality Management, Vol. 22(5), pp. 693-717.

Khan, Muhammad Riaz, Ziauddin, Farooq Ahmed Jam, and Muhammad Ismail Ramay. (2010). The Impact of Organizational Commitment on Employee Job Performance. European Journal of Social Sciences, Vol. 15(3), pp. 292-298.

Kiasatina, Noor A. (2015). Pengaruh Kecerdasan Emosional Dan Karakteristik Pekerjaan Terhadap Kepuasan Kerja Karyawan PT. Mirota Kampus Yogyakarta. Published Skripsi S1, Universitas Negeri Yogyakarta, Yogyakarta.

Koesmono, H. T. (2005). Pengaruh Budaya Organisasi Terhadap Motivasi Dan Kepuasan Kerja Serta KinerjaKaryawan Pada Sub Sektor Industri Pengolahan Kayu Skala Menengah Di Jawa Timur. Jurnal Manajemen Dan Kewirausahaan, Vol. 7(2), pp. 171-188.

Kreitner, Robert dan Angelo Kinicki. (2005). Perilaku Organisasi (Organizational Behavior. Jakarta : Salemba Empat.

Luthans, Fred. (2006). Perilaku Organisasi. Diterjemahkan oleh Vivin Andika Yuwono dkk, Edisi Pertama. Yogyakarta: Andi.

Mahesa, Deewar. (2010). Analisis Pengaruh Motivasi Dan Kepuasan Kerja Terhadap Kinerja Karyawan Dengan Lama Kerja Sebagai Variabel Moderating (Studi Pada PT. Coca Cola Amatil Indonesia (Central Java). Published Skripsi S1, Universiatas Diponegoro, Semarang.

Mangkunegara, Anwar P. (2000). Manajemen Sumber Daya Manusia Perusahaan. Bandung : PT Remaja Rosdakarya Offset Bandung.

Mas`ud, Fuad. (2004). Survai Diagnosis Organisasional, Konsep \& Aplikasi. Semarang : Badan Penerbit Universitas Diponegoro.

McNeese-Smith and Donna. (1996). Increasing Employee Productivity, Job Satisfaction, and OrganizationalCommitment. Hospital \& Health Services Administration, Vol. 41(2), pp. 160-175

Morrison. (1997). How Franchise Job Satisfaction and Personality Affects Performance, Organizational Commitment, Franchisor Relation, and Intention to Remain. Journal of Small Business Management, July.

Nurhayati, Agustina E. (2013). Pengaruh Kepuasan Kerja, Motivasi, Dan Persepsi Atas Dukungan Organisasional Terhadap Komitmen Organisasi Guru Taman KanakKanak Di Kecamatan Sanden, Kabupaten Bantul, Yogyakarta. Unpublished Skripsi S1, Universitas Sarjanawiyata Tamansiswa, Yogyakarta.

Octaviana, Nur. (2011). Pengaruh Budaya Organisasi Terhadap Motivasi Dan Kepuasan Kerja Serta KinerjaKaryawan (Pada PT. Mirota Kampus Yogyakarta). Published Skripsi S1, Universiatas Pembangunan Nasional, Yogyakarta. 
Pangestu, Anita A. (2014). Pengaruh Kepuasan Kerja Dan Komitmen Organisasional Terhadap Kinerja Pegawai (Studi Pada BNI KCU Semarang). Published Skripsi S1, Universitas Diponegoro, Semarang.

Robbins, Stephen P. dan Timothy A. Judge. (2008). Perilaku Organisasi (Organizational Behavior).Jakarta : Salemba Empat.

Rozikin, Khairun. (2012). Pengaruh Komitmen Organisasi Terhadap Kinerja Karyawan Pada PTPerkebunan Nusantara IV Medan Unit Kebun Pabatu. Unpublished Skripsi S1, Universiatas Sumatera Utara, Medan.

Rivai, Veithzal. (2004). Manajemen Sumber Daya Manusia Untuk Perusahaan. Jakarta : PT Raja Grafindo Persada.

Sigit, Soehardi. (2003). Esensi Perilaku Organisasional. Yogyakarta : Fakultas Ekonomi Universitas Sarjanawiyata Tamansiswa.

Tania, Anastasia dan Eddy M. Susanto. (2013). Pengaruh Motivasi Kerja Dan Kepuasan Kerja Terhadap Komitmen Organisasional Karyawan PT. Dai Knife Di Surabaya. Jurnal Agora, Vol 1(3).

Wahab, Rahmatullah B. (2012). Pengaruh Kepuasan Dan Motivasi Kerja Terhadap Kinerja Karyawan Pada PT. Bank Mandiri (Persero) Tbk Makassar. Unpublished Skripsi S1, Universiatas Hasanuddin, Makassar.

Wardhani, Winda K., Susilo H., Iqbal M. (2015). Pengaruh Motivasi Kerja Karyawan Terhadap Komitmen Organisasional Dengan Kepuasan Kerja Sebagai Variabel Intervening. Jurnal Administrasi Bisnis, Vol. 2(1).

Wirawan. (2009). Evaluasi Kinerja Sumber Daya Manusia. Jakarta : Salemba Empat.

Wiyono, Genro. (2011). Merancang Penelitian Bisnis Dengan Alat Analisis SPSS 17.0 Dan SmartPLS 2.0. Yogyakarta : UPP STIM YKPN.

Yousef, Darwish A. (2002). Job Satisfaction as a Mediator of the Relationship between Role Stressors and Organizational Commitment: A Study from an Arabic Cultural Perspective. Journal of Managerial Psychology, Vol. 17(4), pp. 250-266. 